\title{
A novel method to extend SAW for decision-making problems with interval data
}

\author{
Alireza Salehi* and Mohammad Izadikhah
}

Department of Mathematics, Islamic Azad University, Arak-branch, Arak, Iran

\begin{tabular}{|c|c|}
\hline CHRON I C LE & A B S T RACT \\
\hline $\begin{array}{l}\text { Article history: } \\
\text { Received January 15, } 2013 \\
\text { Accepted October 12, } 2013 \\
\text { Available online } \\
\text { November } 42013 \\
\text { Keywords: } \\
\text { SAW method } \\
\text { Interval data } \\
\text { Entropy method } \\
\text { Multiple Criteria Decision- }\end{array}$ & $\begin{array}{l}\text { Decision making problem is the process of finding the best option out of all feasible } \\
\text { alternatives. There are some methods for solving Multiple Criteria Decision-Making problems } \\
\text { and Simple Additive Weighting (SAW) is one of the most popular ones. In this paper, among } \\
\text { multi-criteria models in making complex decisions and multiple attribute models for the most } \\
\text { preferable choice, SAW technique is extended using interval numbers. For this purpose, we first } \\
\text { propose a method for extending Entropy method for dealing with interval data, and then the } \\
\text { extended SAW method with interval data is proposed by using the interval weights derived by } \\
\text { the proposed interval Entropy method. The extended SAW method is an algorithm to determine } \\
\text { the most preferable choice out of all possible choices, when the input data are stated in interval. }\end{array}$ \\
\hline
\end{tabular}

\section{Introduction}

Decision-making problem is considered as a process of detecting the best alternative from all of the feasible alternatives. Multi-Attribute Decision Making (MADM) along with multi-objective decision making (MODM) are the most well-known categories of decision making, which is a branch of a general class of multi-criteria decision making (MCDM) in operations research models and they deal with decision problems under the presence of a number of decision criteria (Zeleny, 1982; Zimmermann, 1991). Multi-criteria optimization is the process of determining the best feasible solutions based on various criteria. Practical problems are often characterized by several noncommensurable and conflicting criteria and there may be no solution satisfying all criteria, simultaneously. The solution is normally a set of non-inferior solutions, or a compromise solution based on the decision maker's preferences. The compromise solution was established by Yu (1973) for a problem with conflicting criteria and helps the decision makers reach a desirable solution. The compromise solution is a feasible solution, which is the closest to the ideal, and finds an agreement

* Corresponding author.

E-mail addresses: a lireza.salehi91@yahoo.com (A. Salehi)

(C) 2014 Growing Science Ltd. All rights reserved. doi: $10.5267 /$ j.ds1.2013.11.001 
established by mutual concessions. A MCDM problem can be concisely expressed in matrix format as follows,

\begin{tabular}{c|cccc} 
& $\mathrm{C}_{1}$ & $\mathrm{C}_{2}$ & $\ldots$ & $\mathrm{C}_{\mathrm{n}}$ \\
\hline $\mathrm{A}_{1}$ & $\mathrm{X}_{11}$ & $\mathrm{X}_{12}$ & & $\mathrm{X}_{1 \mathrm{n}}$ \\
$\mathrm{A}_{2}$ & $\mathrm{X}_{21}$ & $\mathrm{X}_{22}$ & \\
$\cdot$ & & & \\
$\cdot$ & & & $\mathrm{X}_{2 \mathrm{n}}$ \\
$\mathrm{A}_{\mathrm{m}}$ & $\mathrm{X}_{\mathrm{m} 1}$ & $\mathrm{X}_{\mathrm{m} 1}$ & $\mathrm{X}_{\mathrm{mn}}$
\end{tabular}

where $A_{1}, A_{2}, \ldots, A_{m}$ are possible alternatives among which decision makers have to choose, $\mathrm{C}_{1}, \mathrm{C}_{2}$, . $\ldots, \mathrm{C}_{\mathrm{n}}$ are criteria in which alternative performance are measured, $\mathrm{x}_{\mathrm{ij}}$ is the rating of alternative $\mathrm{A}_{\mathrm{i}}$ with respect to criterion $C_{j}$ and finally $w_{j}$ is the weight of criterion $C_{j}$.

The main steps of multiple criteria decision making are the follows:

(a) Establishing system evaluation criteria associated with system capabilities based on the goals,

(b) Developing alternative systems for attaining the goals (generating Alternatives),

(c) Evaluating alternatives in terms of criteria (the values of the criterion functions),

(d) Applying a normative multi-criteria analysis method,

(e) Accepting one alternative as "optimal”' (preferred),

(f) If the final solution is not accepted, gather new information and go into the next iteration of multicriteria optimization.

Steps (a) and (e) are performed at the upper level, where decision makers play essential role and the other steps are mostly engineering tasks. For step (d), a decision maker should express his/her preferences in terms of the relative importance of criteria, and one approach is to introduce criteria weights. This weight in MCDM do not have a clear economic significance, but the weights provide the opportunity to model the actual aspects of decision making (the preference structure). In classical MCDM methods, the ratings and the weights of the criteria are known precisely (Dyer et al., 1992; Hwang \& Yoon, 1981). In MCDM problems, since the valuation of criteria leads to diverse opinions and meanings, each attribute should be imported with a specific importance weight (Chen et al., 2003). A question rises up here is "how this importance weight could be calculated"? In literature, most of the typical MCDM methods leave this part to decision makers, while sometimes it would be useful to engage end-users into the decision making process. To obtain a better weighting system, we may categorize weighting methods into two categories including subjective methods and objective methods (Wang \& Lee, 2009). While subjective methods determine weights solely based on the preference or judgments of decision makers, objective methods utilize mathematical models, such as entropy method or multiple objective programming, automatically without considering the decision makers' preferences. The approach with objective weighting is particularly applicable for situations where reliable subjective weights cannot be obtained (Deng et al., 2000)

Simple Additive Weighting (SAW) is the oldest, most widely known and practically used method (Hwang \& Yoon, 1981; Chu et al., 2007; Ginevičius \& Podvezko, 2008a, 2008b, 2008c; Ginevičius \& Ginevičiene, 2009; Zavadskas et al., 2007; Jakimavičius \& Burinskiene, 2009; Podvezko et al., 2010; Sivilevicius, et al., 2008). SAW is also known as weighted linear combination or scoring methods, which is a simple and sophisticated method used among MCDM problems and the method 
is based on the weighted average. An evaluation score is calculated for each alternative by multiplying the scaled value given to the alternative of that attribute with the weights of relative importance directly assigned by decision maker followed by summing of the products for all criteria. The advantage of this method is that it is a proportional linear transformation of the raw data, which means that the relative order of magnitude of the standardized scores remains equal (Afshari, et al., 2010).In this new method, we try to use entropy method with interval data for development of SAW method with interval data. Entropy method is generalized for interval data and it is used for getting interval weights in SAW method.

The rest of this paper is organized as follows: The following section provides some required preliminaries. The third section of the paper gives an extension of the Entropy method with interval data. In the fourth section the proposed SAW method with interval data is presented, one numerical example is presented in section 5. The paper ends with conclusion.

\section{Preliminaries}

\subsection{Shannon entropy and objective weights}

As mentioned earlier, two different weights are used in the proposed method: objective weights and subjective weights. Subjective weights could be obtained directly from the decision makers' opinions like many other MCDM processes. Shannon (2001) proposed the entropy concept, which is a measure of uncertainty in information formulated in terms of probability theory. Since the entropy concept is well suited for measuring the relative contrast intensities of criteria to represent the average intrinsic information transmitted to the decision maker (Zeleny, 1982). Conveniently, it would be a proper option for our purpose. Later research has applied this measure to a wide range of applications including

1 Spectral analysis (Burg, 1967);

2 Language modeling (Rosenfeld, 2005)

3 Economics (Judge \& Miller, 1996).

\subsection{Entropy weighting method}

The entropy weighting method (Zeleny, 1982) can effectively measure the average essence of information quantity, and the larger the entropy value, the lower the information express quantity (Zeleny, 1982, Feng \& Chen, 1992). This paper tries to solve the objective weight of objective subcriteria, e.g. return on assets, above the alternative level. Thus, it can represent actual conditions of decision-making, and express the explanation ability and reliability of sub-criteria. The steps can be summarized as follows:

Step 1. Allow xij, $i=1,2, \ldots, m ; j=1,2, \ldots, n$, to be the superiority rating of the ith alternative under jth criterion above the alternative level. Then we can define

$$
X=\left[x_{i j}\right]_{m \times n} \quad i=1, \ldots, m, j=1, \ldots, n
$$

and we call $X$ as decision matrix.

Step 2. Form normal decision matrix $R=\left[r_{i j}\right]_{m \times n}$, where 
$\forall i, j, r_{i j}=\frac{x_{i j}}{\sum_{i=1}^{m} x_{i j}}$

Step 3. Calculation of concentration index for per criteria's data as follows,

$$
E_{j}=-\frac{1}{\ln (m)} \sum_{i=1}^{m} r_{i j} \ln \left(r_{i j}\right), j=1, \ldots, n
$$

In Eq. (3), lower value for $E_{j}$ implies less concentration of data $C_{j}$ criteria and more dispersal of its data.

Step 4. Determination the amount of per criteria's Dispersal

The amount of per criteria's Dispersal calculated as following:

$d_{j}=1-E_{j} \quad j=1, \ldots, n$

Step 5. Calculation the weight of criteria

The weight of criteria calculated as following:

$$
W_{j}=\frac{d_{j}}{\sum_{j=1}^{n} d_{j}} \quad j=1, \ldots, n
$$

Therefore, we have, $0 \leq w_{j} \leq 1, j=1, \cdots, 1$.

\subsection{The SAW method}

The criterion of the method $S_{j}$ clearly demonstrates the main concept of MCDM for the integration of the criteria values and weights into a single magnitude. This is also reflected in its name. The sum $S_{j}$ of the weighted normalized values of all the criteria is calculated for the $j$-th object:

$$
S_{J}=\sum_{J=1}^{m} w_{j} \tilde{r}_{i j}
$$

where $\omega_{i}$ is the weight of the $\mathrm{i}$-th criterion $\left(\sum_{\mathrm{i}=1}^{\mathrm{m}} \mathrm{w}_{\mathrm{i}}\right), \widetilde{\mathrm{r}_{1 j}}$ is the normalized $\mathrm{i}-$ th criterion's value for $\mathrm{j}-$ th object; $i=1, \ldots, m ; j=1, \ldots, n ; m$ is the number of the criteria used and finally $n$ is the number of the objects (alternatives) compared. The largest value of the criterion $S_{j}$ corresponds to the best alternative. The alternatives compared should be ranked in non-increasing order of the calculated values of the criterion $S_{j}$.

SAW may be used if all the criteria are maximizing type. This is a drawback of this method, though minimizing criteria can be easily converted to the maximizing ones by the formula:

$\bar{r}_{i j}=\frac{\min _{j}\left(r_{i j}\right)}{r_{i j}}$,

where $r_{i j}$ is $\mathrm{i}$-th criterion's value for $\mathrm{j}$-th alternative, $\min _{\mathrm{j}} \mathrm{r}_{\mathrm{ij}}$ is the smallest $\mathrm{i}$-th criterion's value for all the alternatives compared, rij denotes the converted values. Thus, the smallest criterion value $\widetilde{r_{1 j}}=\min _{j} r_{i j}$ acquires the largest value equal to unity. 
In many papers (Hwang \& Yoon, 1981; Zavadskas et al., 2008), normalization (or transformation) of the initial data is used, so that the best criterion value (the largest one for a maximizing criterion and the smallest one for a minimizing criterion) would get the largest value equal to unity. As mentioned above, it is recommended to use Eq. (2) for transforming minimizing criteria. The transformation formula used for maximizing criteria is as follows:

$$
\overline{r_{i j}}=\frac{r_{i j}}{\max _{j} r_{i j}},
$$

where $\max _{j} r_{i j}$ is the largest $\mathrm{i}$-th criterion's value of all alternatives.

\subsection{Interval data}

Considering the fact that, in some cases, determining the exact value of the attributes is difficult and that, as a result of this, their values are considered as intervals, therefore, now we try to extend SAW for these interval data. Suppose $A_{1}, A_{2}, \ldots, A_{m}$ are $m$ possible alternatives among which decision makers have to choose, $C_{1}, C_{2}, \ldots, C_{n}$ are criteria in which alternative performance are measured, $X_{i j}$ is the rating of alternative $A_{i}$ with respect to criterion $C_{j}$ and is not known exactly and only we know $X_{i j} \in\left[X_{i j}{ }^{L}, X_{i j}{ }^{U}\right]$. An MCDM problem with interval data can be concisely expressed in matrix format as follows,

\begin{tabular}{|c|c|c|c|}
\hline & $\mathrm{C}_{1}$ & $\mathrm{C}_{2}$ & $\mathrm{C}_{\mathrm{n}}$ \\
\hline $\mathrm{A}_{1}$ & {$\left[\mathrm{X}^{\mathrm{L}}{ }_{11}, \mathrm{X}^{\mathrm{U}}{ }_{11}\right]$} & {$\left[\mathrm{X}_{12}^{\mathrm{L}}, \mathrm{X}^{\mathrm{U}}{ }_{12}\right]$} & {$\left[\mathrm{X}^{\mathrm{L}}{ }_{\mathrm{n}}, \mathrm{X}^{\mathrm{U}}{ }_{1 \mathrm{n}}\right]$} \\
\hline $\mathrm{A}_{2}$ & {$\left[\mathrm{X}^{\mathrm{L}}{ }_{21}, \mathrm{X}^{\mathrm{U}}{ }_{21}\right]$} & {$\left[\mathrm{X}_{22}^{\mathrm{L}}, \mathrm{X}^{\mathrm{U}}{ }_{22}\right]$} & {$\left[\mathrm{X}_{2 \mathrm{n}}^{\mathrm{L}}, \mathrm{X}^{\mathrm{U}}{ }_{2 \mathrm{n}}\right]$} \\
\hline$A_{m}$ & {$\left[\mathrm{X}^{\mathrm{L}}{ }_{\mathrm{ml}}, \mathrm{X}^{\mathrm{U}}{ }_{\mathrm{ml}}\right]$} & {$\left[\mathrm{X}^{\mathrm{L}}{ }_{\mathrm{m} 2}, \mathrm{X}^{\mathrm{U}}{ }_{\mathrm{m} 2}\right]$} & {$\left[\mathrm{X}^{\mathrm{L}}{ }_{\mathrm{mn}}, \mathrm{X}^{\mathrm{U}}{ }_{\mathrm{mn}}\right]$} \\
\hline
\end{tabular}

$\mathrm{W}=\left[\mathrm{w}_{1}, \ldots, \mathrm{w}_{\mathrm{n}}\right]$

where $W_{j}$ is the weight of criterion $C_{j}$.

Considering the fact that, in some cases, determining the exact value of the elements of decision matrix is difficult and, as a result, their values are considered as intervals, therefore, we try to extend SAW for these interval data.

Definition 1. Let B be an interval number on the real line $R$ and it is expressed as follows,

$$
B=\left[b^{l}, b^{u}\right]=\left\{b: b^{l} \leq b \leq b^{u}, b \in R\right\} .
$$

If $b^{l}=b^{u}$ then $b$ is a real number.

Suppose $A_{1}, A_{2}, \ldots, A_{m}$ are $m$ possible alternatives in which decision makers have to choose, $C_{1}, C_{2}$ ,..., $C_{n}$ criteria in which alternative performance is measured, $X_{i j}$ is the rating of alternative $A_{i}$ with respect to criterion $C_{j}$ and is not known exactly and only we know $\mathrm{X}_{\mathrm{ij}} \in[\mathrm{XijL}, \mathrm{XijU}]$. 


\subsubsection{Comparison between intervals}

In interval efficiency assessment, since the final efficiency score for each DMU is characterized by an interval, a simple yet practical ranking approach is required for comparing and ranking the efficiencies of different DMUs. There are some approaches developed earlier to rank interval numbers, but they all have some shortcomings. Especially, when the interval numbers have the same center but different widths, they all fail to distinguish one from another. Interested readers may refer to Wang et al. (2005) for more discussions on the existing approaches.

Here we introduce the minimax regret approach (MRA) developed by Wang et al. (2005). The approach has some attractive features and can be used to compare and rank the efficiency intervals of DMUs even if they are equi-centered but different in widths. The approach is summarized as follows.

Let $A_{i}=\left[a_{i}^{L}, a_{i}^{U}\right]=\left\langle m\left(A_{i}\right), w\left(A_{i}\right)\right\rangle(i=1, \ldots, n)$ be the efficiency intervals of $n$ DMUs, where $m\left(A_{i}\right)=\frac{1}{2}\left(a_{i}^{U}+a_{i}^{L}\right)$ and $w\left(A_{i}\right)=\frac{1}{2}\left(a_{i}^{U}-a_{i}^{L}\right)$ are their midpoints (centers) and widths. Without loss of generality, suppose $A_{i}=\left[a_{i}^{L}, a_{i}^{U}\right]$ is selected as the best efficiency interval. Let $b=$ $\max _{j \neq i}\left\{a_{i}^{U}\right\}$. Obviously, if $a_{i}^{L}<b$, the DM might suffer the loss of efficiency (also called the loss of opportunity or regret) and feel regret. The maximum loss of efficiency he/she might suffer is given by

$\max \left(r_{i}\right)=b-a_{i}^{L}=\max _{j \neq i}\left\{a_{j}^{u}\right\}-a_{i}^{L}$.

If $a_{i}^{L} \geq b$, the DM will definitely suffer no loss of efficiency and feel no regret. In this situation, his/her regret is defined to be zero, i.e. $r_{i}=0$, Combining the above two situations yields,

$\max \left(r_{i}\right)=\max \left[\max _{j \neq i}\left(a_{j}^{u}\right)-a_{i}^{L}, 0\right]$

Thus, the minimax regret criterion will choose the efficiency interval satisfying the following condition as the best (most desirable) efficiency interval:

$$
\min _{i}\left\{\max \left(r_{i}\right)\right\}=\min _{i}\left\{\max \left[\max _{j \neq i}\left(a_{j}^{u}\right)-a_{i}^{L}, 0\right]\right\}
$$

Based on the analysis above, we give the following definition for comparing and ranking efficiency intervals.

Definition 2. Let $A_{i}=\left[a_{i}^{L}, a_{i}^{U}\right]=\left\langle m\left(A_{i}\right), w\left(A_{i}\right)\right\rangle(i=1, \ldots, n)$ be a set of efficiency intervals. The maximum loss of efficiency (also called maximum regret) of each efficiency interval $A_{i}$ is defined as

$$
R_{i}=\max \left[\max _{j \neq i}\left(a_{j}^{u}\right)-a_{i}^{L}, 0\right]=\max \left[\max _{j \neq i}\left\{m\left(A_{i}\right)+w\left(A_{i}\right)\right\}-\left(m\left(A_{i}\right)-w\left(A_{i}\right)\right), 0\right] ; i=1, \ldots, n
$$

It is evident that the efficiency interval with the smallest maximum loss of efficiency is the most desirable efficiency interval.

\section{Entropy method with interval data}

Step1. Suppose $A_{1}, A_{2}, \ldots, A_{m}$ are m possible alternatives among which decision makers have to choose, $C_{1}, C_{2}, \ldots, C_{n}$ are criteria with which alternative performance are measured, $X_{i j}$ is the rating of alternative $\mathrm{Ai}$ with respect to criterion $C_{j}$ and is not known exactly and only we know $X_{i j} \in\left[X_{i j}{ }^{L}, X_{i j}{ }^{U}\right]$. A MCDM problem with interval data can be concisely expressed in matrix format as follows, 


\begin{tabular}{|c|c|c|c|}
\hline & $\mathrm{C}_{1}$ & $\mathrm{C}_{2}$ & $\mathrm{C}_{\mathrm{n}}$ \\
\hline $\mathrm{A}_{1}$ & {$\left[\mathrm{X}_{11}^{\mathrm{L}}, \mathrm{X}^{\mathrm{U}}{ }_{11}\right]$} & {$\left[\mathrm{X}^{\mathrm{L}}{ }_{12}, \mathrm{X}^{\mathrm{U}}{ }_{12}\right]$} & {$\left[\mathrm{X}^{\mathrm{L}}{ }_{1 \mathrm{n}}, \mathrm{X}^{\mathrm{U}}{ }_{1 \mathrm{n}}\right]$} \\
\hline $\mathrm{A}_{2}$ & {$\left[\mathrm{X}^{\mathrm{L}}{ }_{21}, \mathrm{X}^{\mathrm{U}}{ }_{21}\right]$} & {$\left[\mathrm{X}^{\mathrm{L}}{ }_{22}, \mathrm{X}^{\mathrm{U}}{ }_{22}\right]$} & {$\left[\mathrm{X}_{2 \mathrm{n}}^{\mathrm{L}}, \mathrm{X}^{\mathrm{U}}{ }_{2 \mathrm{n}}\right]$} \\
\hline . & & & \\
\hline$A_{m}$ & {$\left[\mathrm{X}_{\mathrm{m} 1}^{\mathrm{L}}, \mathrm{X}_{\mathrm{m} 1}^{\mathrm{U}}\right]$} & {$\left[\mathrm{X}_{\mathrm{m} 2}^{\mathrm{L}}, \mathrm{X}_{\mathrm{m} 2}^{\mathrm{U}}\right]$} & {$\left[\mathrm{X}^{\mathrm{L}}{ }_{\mathrm{mn}}, \mathrm{X}^{\mathrm{U}}{ }_{\mathrm{mn}}\right]$} \\
\hline
\end{tabular}

Step 2. Now we calculate the normalized decision matrix as follows: The normalized values $\overline{\mathrm{n}_{\mathrm{lj}}^{\mathrm{j}}}$ and $\overline{\mathrm{n}_{\mathrm{lj}}^{\mathrm{U}}}$ are calculated as

$$
\begin{gathered}
\bar{n}_{i j}^{L}=\frac{x_{i j}^{L}}{\sum_{J=1}^{m}\left(x_{i j}^{L}\right)+\left(x_{i j}^{U}\right)} \quad j=1, \ldots, m, i=1, \ldots, n \\
\bar{n}_{i j}^{U}=\frac{x_{i j}^{U}}{\sum_{J=1}^{m}\left(x_{i j}^{L}\right)+\left(x_{i j}^{U}\right)} \quad j=1, \ldots, m, i=1, \ldots, n
\end{gathered}
$$

This normalization is the norm $\mathrm{L}_{1}$ version of the normalization method proposed in (Jahanshahloo et al., 2006). Now interval $\left[\overline{\mathrm{n}_{\mathrm{j}}^{\mathrm{L}}}, \overline{\mathrm{n}_{\mathrm{lj}}^{\mathrm{U}}}\right]$ is the normalized of interval $\left[\mathrm{X}_{\mathrm{ij}}^{\mathrm{L}}, \mathrm{X}_{\mathrm{ij}}^{\mathrm{U}}\right]$. The normalization method mentioned above is to preserve the property that the ranges of normalized interval numbers belong to $[0,1]$.

Step 3. Calculation of concentration index for per criteria's with interval data

This is accomplished by solving the following two non-linear models:

$$
E_{j}^{L}=\min \left(-\frac{1}{\ln (m)}\right) \sum_{i=1}^{m} x_{i j}^{U} \ln \left(x_{i j}^{U}\right)
$$

subject to

$$
\begin{array}{r}
\bar{n}_{i j}^{L} \leq x_{i j} \leq \bar{n}_{i j}^{U} \quad i=1, \ldots, m \\
E_{j}^{U}=\max \left(-\frac{1}{\ln (m)}\right) \sum_{i=1}^{m} x_{i j}^{L} \ln \left(x_{i j}^{L}\right)
\end{array}
$$

subject to

$$
\bar{n}_{i j}^{L} \leq x_{i j} \leq \bar{n}_{i j}^{U} \quad i=1, \ldots, m
$$

After some simple calculation we have,

$$
\begin{aligned}
& E_{j}^{L}=\left(-\frac{1}{\ln (m)}\right) \sum_{i=1}^{m} n^{U}{ }_{i j} \ln \left(n^{U}{ }_{i j}\right), \\
& E_{j}^{U}=\left(-\frac{1}{\ln (m)}\right) \sum_{i=1}^{m} n^{L}{ }_{i j} \ln \left(n^{L}{ }_{i j}\right) .
\end{aligned}
$$

Therefore, we have $E_{j}^{L} \leq E_{j}^{U}$. 
Step 4. The amount of per criteria's Dispersal

$$
\begin{aligned}
& d_{j}^{L}=1-E_{j}^{U} \\
& d_{j}^{U}=1-E_{j}^{L}
\end{aligned}
$$

Therefore, we have $d_{j}^{L} \leq d_{j}^{U}$

Step 5. Calculation weight of criteria

Same as normalization method mentioned in section 3, we can obtain the weights as follows:

$$
\begin{aligned}
& W_{j}^{L}=\frac{d_{j}^{L}}{\sum_{J=1}^{n}\left(d_{j}^{L}+d_{j}^{U}\right)}, \\
& W_{j}^{U}=\frac{d_{j}^{U}}{\sum_{J=1}^{n}\left(d_{j}^{L}+d_{j}^{U}\right)} .
\end{aligned}
$$

Therefore, we $w_{j}^{L} \leq w_{j}^{U}$ and the interval weight of criterion $\mathrm{Cj}$ is $\left[w_{j}^{L}, w_{j}^{U}\right]$.

\section{SAW method with interval data}

Considering the fact that, in some cases, determining the exact value of the attributes is difficult and that, as a result of this, their values are considered as intervals, therefore, now we try to extend SAW for these interval data. Suppose $A_{1}, A_{2}, \ldots, A_{m}$ are $\mathrm{m}$ possible alternatives among which decision makers have to choose, $C_{1}, C_{2}, \ldots, C_{n}$ are criteria with which alternative performance are measured,

\begin{tabular}{|c|c|c|c|}
\hline & $\mathrm{C}_{1}$ & $\mathrm{C}_{2}$ & $\mathrm{C}_{\mathrm{n}}$ \\
\hline $\mathrm{A}_{1}$ & {$\left[\mathrm{X}^{\mathrm{L}}{ }_{11}, \mathrm{X}_{11}^{\mathrm{U}}\right]$} & {$\left[\mathrm{X}^{\mathrm{L}}{ }_{12}, \mathrm{X}^{\mathrm{U}}{ }_{12}\right]$} & {$\left[\mathrm{X}_{1 \mathrm{n}}^{\mathrm{L}}, \mathrm{X}^{\mathrm{U}}{ }_{1 \mathrm{n}}\right]$} \\
\hline $\mathrm{A}_{2}$ & {$\left[\mathrm{X}^{\mathrm{L}}{ }_{21}, \mathrm{X}^{\mathrm{U}}{ }_{21}\right]$} & {$\left[\mathrm{X}^{\mathrm{L}}{ }_{22}, \mathrm{X}^{\mathrm{U}}{ }_{22}\right]$} & {$\left[\mathrm{X}^{\mathrm{L}}{ }_{2 \mathrm{n}}, \mathrm{X}^{\mathrm{U}}{ }_{2 \mathrm{n}}\right]$} \\
\hline$\cdot$ & & & \\
\hline$A_{m}$ & {$\left[\mathrm{X}^{\mathrm{L}}{ }_{\mathrm{m} 1}, \mathrm{X}_{\mathrm{m} 1}^{\mathrm{U}}\right]$} & {$\left[\mathrm{X}^{\mathrm{L}}{ }_{\mathrm{m} 2}, \mathrm{X}^{\mathrm{U}}{ }_{\mathrm{m} 2}\right]$} & {$\left[\mathrm{X}^{\mathrm{L}}{ }_{\mathrm{mn}}, \mathrm{X}^{\mathrm{U}}{ }_{\mathrm{mn}}\right]$} \\
\hline
\end{tabular}
$X_{i j}$ is the rating of alternative $\mathrm{Ai}$ with respect to criterion $C_{j}$ and is not known exactly and only we know $\mathrm{X}_{\mathrm{ij}} \in\left[\mathrm{X}_{\mathrm{ij}}^{\mathrm{L}}, \mathrm{X}_{\mathrm{ij}}^{\mathrm{U}}\right]$. A MCDM problem with interval data can be concisely expressed in matrix format as

$W=\left[w_{1} ; w_{2} ; \ldots ; w_{n}\right]$

Where $w_{j}$ is the weight of criterion $C_{j}$.

\subsection{The proposed algorithmic method}

A systematic approach to extend the SAW to the interval data is proposed in this section. This approach the following steps:

Step 1. Establish decision making matrix with interval data, 
Step 2. Determine the weights of criteria according to section 4, by using the interval Entropy method discussed in section 3. We assume that the interval weight for criterion $C_{j}$ is $\left[w_{j}^{L}, w_{j}^{U}\right]$.

Step 3. Establishment of normal of decision making matrix with interval data.

In order to establishment of normal decision making matrix, we use two different methods for calculation of normal value for benefit and cost criteria. So that both criteria will be considered as benefit criteria these normalizations are as follows:

$$
\begin{aligned}
& \left\{\begin{array}{l}
\bar{n}_{i j}^{L}=\frac{x_{i j}^{L}}{\sum_{J=1}^{m}\left(x_{i j}^{L}\right)+\left(x_{i j}^{U}\right)} \quad j=1, \ldots, m, i=1, \ldots, n j \in B \\
\bar{n}_{i j}^{U}=\frac{x_{i j}^{U}}{\sum_{J=1}^{m}\left(x_{i j}^{L}\right)+\left(x_{i j}^{U}\right)} j=1, \ldots, m, i=1, \ldots, n j \in B
\end{array}\right. \\
& \left\{\begin{array}{l}
\bar{n}_{i j}^{L}=\frac{\frac{1}{x_{i j}^{U}}\left(\frac{1}{x_{i j}^{L}}\right)+\left(\frac{1}{x_{i j}^{U}}\right)}{x^{m}} j=1, \ldots, m, i=1, \ldots, n j \in C \\
\bar{n}_{i j}^{U}=\frac{1}{\sum_{J=1}^{m}\left(\frac{1}{x_{i j}^{L}}\right)+\left(\frac{1}{x_{i j}^{U}}\right)} \quad j=1, \ldots, m, i=1, \ldots, n j \in C
\end{array}\right.
\end{aligned}
$$

$\left[\overline{n_{l j}^{L}}, \overline{n_{l \jmath}^{u}}\right]$ is normalized of the $\left[x_{i j}^{L}, x_{i j}^{U}\right]$ of interval decision matrix. Therefore, we call $N=\left(\left[n_{i j}^{L}, n_{i j}^{U}\right]\right)$ as normalized interval decision matrix.

Step 4. The calculation of utility function for each index

Forming this normalized interval decision matrix yields the utility functions for each alternative as follows,

$$
P^{L}\left(A_{i}\right)=\frac{\sum_{j=1}^{n} \bar{n}_{i j}^{L} W_{j}^{L}}{\sum_{j=1}^{n}\left(W_{j}^{U}+W_{j}^{L}\right)}, P^{U}\left(A_{i}\right)=\frac{\sum_{j=1}^{n} \bar{n}_{i j}^{U} W_{j}^{U}}{\sum_{j=1}^{n}\left(W_{j}^{U}+W_{j}^{L}\right)}
$$


$P^{L}\left(A_{i}\right) \leq P^{U}\left(A_{i}\right), i=1, \ldots, m$. It is obvious that, we have $P^{L}\left(A_{i}\right) \leq P^{U}\left(A_{i}\right), i=1, \ldots, m$. Therefore, for each $A_{i}$ we construct an interval utility function $\left[P^{L}\left(A_{i}\right), P^{U}\left(A_{i}\right)\right]$.

Step 5. Ranking the alternatives

Considering there is an interval utility function $\left[P^{L}\left(A_{i}\right), P^{U}\left(A_{i}\right)\right]$ for each Ai we have to rank all the intervals. In order to this purpose we use in (Wang et al., 2005).

\section{Empirical example}

To illustrate how to use proposed approach, this study selects a small example using data given by Jahanshahloo et al. (2009) we examine the proposed model for six cities in Iran to find the best place for creating a date factory. These cities must be evaluated based on four criteria, two of them are cost oriented $\left(C_{1}, C_{2}\right)$ and the others are benefit oriented $\left(C_{3}, C_{4}\right)$. Criteria are as follows:
$\mathrm{C}_{1}$ : Distance from border $(\mathrm{km})$,
$\mathrm{C}_{3}$ : Finance (percent),
$\mathrm{C}_{2}$ : Cost of creating the factory $(1000 \$)$,
$\mathrm{C}_{4}$ : Product in the region (Ton).

The first criterion is a real number and the others are in interval form. Table 1 represents the data. In Table 1 the normalized data is presented. Since all the criteria have the same importance

\section{Table1}

Data of alternative

\begin{tabular}{ccccc}
\hline City & $\mathrm{C} 1$ & $\mathrm{C} 2$ & $\mathrm{C} 3$ & $\mathrm{C} 4$ \\
\hline city & {$[1451,1451]$} & {$[2551,3118]$} & {$[40,50]$} & {$[153,187]$} \\
city 2 & {$[843,843]$} & {$[3742,4573]$} & {$[63,77]$} & {$[459,561]$} \\
city 3 & {$[1125,1125]$} & {$[3312,4049]$} & {$[48,58]$} & {$[153,187]$} \\
city 4 & {$[55,55]$} & {$[5309,6488]$} & {$[72,88]$} & {$[347,426]$} \\
city 5 & {$[356,356]$} & {$[3709,4534]$} & {$[59,71]$} & {$[151,189]$} \\
city 6 & {$[391,391]$} & {$[4884,5969]$} & {$[72,88]$} & {$[388,474]$} \\
\hline
\end{tabular}

Using Eq. (9), we determine the normalized decision making matrix, the result are showed in following table:

\section{Table 2}

The normalized rates

\begin{tabular}{ccccc}
\hline City & $\mathrm{C} 1$ & $\mathrm{C} 2$ & $\mathrm{C} 3$ & $\mathrm{C} 4$ \\
\hline city 1 & {$[0.1718,0.1718]$} & {$[0.0488,0.0596]$} & {$[0.0508,0.0636]$} & {$[0.0203,0.0248]$} \\
city 2 & {$[0.0998,0.0998]$} & {$[0.0716,0.0875]$} & {$[0.0801,0.0979]$} & {$[0.0610,0.0746]$} \\
city 3 & {$[0.1332,0.1332]$} & {$[0.0634,0.0775]$} & {$[0.0610,0.0737]$} & {$[0.0203,0.0248]$} \\
city 4 & {$[0.0065,0.0065]$} & {$[0.1016,0.1242]$} & {$[0.0916,0.1119]$} & {$[0.0461,0.5676]$} \\
city 5 & {$[0.0421,0.0421]$} & {$[0.0710,0.0867]$} & {$[0.0750,0.0903]$} & {$[0.0200,0.0251]$} \\
city 6 & {$[0.0463,0.0463]$} & {$[0.0934,0.1142]$} & {$[0.0916,0.1119]$} & {$[0.0516,0.0630]$} \\
\hline
\end{tabular}

Using Eqs. (11-13), we determine the interval values of $E j, D j, W j$ for DMU. The result are showed in Table 3 as follows,

\section{Table 3}

The calculation of $E_{J}, D_{J}, W_{J}$

\begin{tabular}{ccccc}
\hline & $\mathrm{C}_{1}$ & $\mathrm{C}_{2}$ & $\mathrm{C}_{3}$ & $\mathrm{C}_{4}$ \\
\hline $\mathrm{E}_{\mathrm{J}}$ & {$[0.6194,0.6194]$} & {$[0.6434,0.7248]$} & {$[0.6456,0.7270]$} & {$[0.3922,0.5390]$} \\
$\mathrm{D}_{\mathrm{J}}$ & {$[0.3805,0.3805]$} & {$[0.2751,0.3565]$} & {$[0.2797,0.3543]$} & {$[0.4609,0.6077]$} \\
$\mathrm{W}_{\mathrm{J}}$ & {$[0.1232,0.1232]$} & {$[0.0890,0.1154]$} & {$[0.0883,0.1147]$} & {$[0.1492,0.1967]$} \\
\hline
\end{tabular}


Using Eq. (15), we calculate interval utility for each city. These values are presented in Table 4 as follows,

\section{Table 4}

The calculation of interval utility and ranking

\begin{tabular}{lcc}
\hline & {$\left[P^{L}\left(A_{i}\right), P^{U}\left(A_{i}\right)\right]$} & Ranking \\
\hline city 1 & {$[0.0330,0.0555]$} & 3 \\
city 2 & {$[0.0348,0.0718]$} & 2 \\
city 3 & {$[0.0305,0.0564]$} & 4 \\
city 4 & {$[0.0248,0.1665]$} & 1 \\
city 5 & {$[0.0211,0.0521]$} & 5 \\
city 6 & {$[0.0298,0.0709]$} & 6 \\
\hline
\end{tabular}

Using MRA method, which is introduced in Step 5, we rank the cities. The results are presented in last column of Table 4 . According to this ranking, city 4 has the best ranking.

\section{Conclusion}

In this paper, we have explained that the natures of many MCDM problems are associated with uncertain data and we need to extend the existing method by considering different techniques to handle uncertainty. This paper extended SAW method where the input data were stated as interval. We have also extended the entropy method for deriving interval weights of criteria. Then, we applied it through the proposed extended SAW method. Finally, we applied the proposed algorithm through numerical example, which is about finding the best place for a new factory in 6 cities of Iran.

\section{References}

Afshari, A., Mojahed, M., \& Yusuff, R. M. (2010). Simple additive weighting approach to personnel selection problem. International Journal of Innovation, Management and Technology, 1(5), 511 515.

Burg, J. P. (1967). Maximum entropy spectral analysis. In 37th Annual International Meeting.. Society of Exploration Geophysics.

Chen, M. F., Tzeng, G. H., \& Ding, C. G. (2003, May). Fuzzy MCDM approach to select service provider. In Fuzzy Systems, 2003. FUZZ'03. The 12th IEEE International Conference on (Vol. 1, pp. 572-577). IEEE.

Chu, M. T., Shyu, J., Tzeng, G. H., \& Khosla, R. (2007). Comparison among three analytical methods for knowledge communities group-decision analysis. Expert systems with applications, 33(4), 1011-1024.

Dyer, J. S., Fishburn, P. C., Steuer, R. E., Wallenius, J., \& Zionts, S. (1992). Multiple criteria decision making, multiattribute utility theory: the next ten years. Management science, 38(5), 645654.

Hwang, C. L., \& Yoon, K. (1981). Multiple attribute decision making. Berlin: Springer.

Deng, H., Yeh, C. H., \& Willis, R. J. (2000). Inter-company comparison using modified TOPSIS with objective weights. Computers \& Operations Research, 27(10), 963-973.

Feng, C. M., \& Chen, C. F. (1992). The determination of criteria weights-compromised weighting method. Traffic and Transportation, 14, 51-67.

Ginevičius, R., \& Podvezko, V. (2008a). Multicriteria graphical-analytical evaluation of the financial state of construction enterprises. Technological and Economic Development of Economy, 14(4), $452-461$. 
Ginevičius, R., \& Podvezko, V. (2008b). Multicriteria evaluation of Lithuanian banks from the perspective of their reliability for clients. Journal of Business Economics and Management, 9(4), 257-267.

Ginevicius, R., \& Podvezko, V. (2008c). Housing in the context of economic and social development of Lithuanian regions. International Journal of Environment and Pollution, 35(2), 309-330.

Ginevičius, R., \& Ginevičiene, V. B. (2009). The compliance of master's degree studies with the economic needs of the country. Technological and Economic Development of Economy, 15(1), $136-153$.

Hwang, C. L., \& Yoon, K. (1981). Multiple attribute decision making. Berlin: Springer.

Jahanshahloo, G. R., Lotfi, F. H., \& Izadikhah, M. (2006). Extension of the TOPSIS method for decision-making problems with fuzzy data. Applied Mathematics and Computation, 181(2), 15441551 .

Jahanshahloo, G. R., Hosseinzadeh Lotfi, F., \& Davoodi, A. R. (2009). Extension of TOPSIS for decision-making problems with interval data: Interval efficiency. Mathematical and Computer Modelling, 49(5), 1137-1142.

Jakimavičius, M., \& Burinskiene, M. (2009). A GIS and multi-criteria-based analysis and ranking of transportation zonesof Vilniuscity. Technological and Economic Development of Economy, 15(1), $39-48$.

Judge, G., \& Miller, D. (1996). Maximum entropy econometrics: Robust estimation with limited data. John Wiley.

Podvezko, V. (2008). Comprehensive evaluation of complex quantities. Business: Theory and Practice, 9(3), 160-168.

Podvezko, V., Mitkus, S., \& Trinkūniene, E. (2010). Complex evaluation of contracts for construction. Journal of Civil Engineering and Management, 16(2), 287-297.

Rosenfeld, R. (2005). Adaptive statistical language modeling: a maximum entropy approach (Doctoral dissertation, IBM).

Sivilevicius, H., Zavadskas, E. K., \& Turskis, Z. (2008). Quality attributes and complex assessment methodology of the asphalt mixing plant. Baltic Journal of Road and Bridge Engineering, 3(3). 161-166.

Shannon, C. E. (2001). A mathematical theory of communication. ACM SIGMOBILE Mobile Computing and Communications Review, 5(1), 3-55.

Wang, Y. M., Greatbanks, R., \& Yang, J. B. (2005). Interval efficiency assessment using data envelopment analysis. Fuzzy sets and Systems, 153(3), 347-370.

Wang, Y. M., Yang, J. B., \& Xu, D. L. (2005). A two-stage logarithmic goal programming method for generating weights from interval comparison matrices. Fuzzy sets and systems, 152(3), 475498.

Wang, T. C., \& Lee, H. D. (2009). Developing a fuzzy TOPSIS approach based on subjective weights and objective weights. Expert Systems with Applications,36(5), 8980-8985.

Yu, P. L. (1973). A class of solutions for group decision problems. Management Science, 19(8), 936946.

Zavadskas, E. K., Turskis, Z., Dejus, T., \& Viteikiene, M. (2007). Sensitivity analysis of a simple additive weight method. International Journal of Management and Decision Making, 8(5), 555574.

Zavadskas, E. K., Kaklauskas, A., Turskis, Z., \& Tamošaitiene, J. (2008). Selection of the effective dwelling house walls by applying attributes values determined at intervals. Journal of Civil Engineering and Management, 14(2), 85-93.

Zeleny, M. (1982). Multiple criteria decision making (Vol. 25). J. L. Cochrane (Ed.). New York: McGraw-Hill.

Zimmermann, H. J. (1991). Fuzzy sets and its applications. 